\title{
Los Estudios Judíos en Argentina y su legitimación en el campo académico: balance $\mathbf{y}$ perspectivas
}

\author{
Dr. Emmanuel N. Kahan \\ emmanuel.kahan@gmail.com \\ IdIHCS-CONICET/NEJ-IDES \\ Dr. Alejandro Dujovne \\ CIS-IDES-CONICET/NEJ-IDES \\ Argentina
}

\section{Resumen}

El reconocimiento de la extensión y complejidad de la inmigración, institucionalización e integración de los judíos a la Argentina hizo de esta experiencia histórica el caso más estudiado dentro del creciente campo de los estudios judíos latinoamericanos. Si bien el interés de investigadores y centros de investigación extranjeros continuó y aumentó con el tiempo, diversos investigadores e investigadoras afiliados a distintas universidades y agencias de investigación argentinas fueron sentando las bases de una tradición local. De este modo, y como se propone mostrar el presente artículo, los estudios judíos producidos desde Argentina han alcanzado una legitimidad en el campo académico local e internacional como consecuencia de una producción sostenida en el tiempo que evidencia las potencialidades de un campo de investigación que al indagar desde diversas disciplinas sobre un actor en particular, los judíos, recompone una serie de perspectivas sobre lo local, lo nacional y lo transnacional. Este trabajo se propone reseñar cuáles fueron los horizontes de indagación y los modos en qué estos desarrollos han posiblitado la visibidad y reconocimiento local de los estudios judíos.

Palabras Clave: Argentina, Estudios Judíos, Universidades, investigación.

\section{Abstract}


The recognition of the extent and complexity of immigration, institutionalization and integration of Jews into Argentina made this historical experience the most studied case in the growing field of Latin American Jewish studies. Although the interest of researchers and foreign research centers continued and increased over the time, several researchers and affiliated researchers from different universities and research agencies in Argentina were laying the foundations of a local tradition. In this way, and as it is proposed to show the present article, the Jewish studies produced from Argentina have reached a legitimacy in the local and international academic field as a result of a sustained production over time that demonstrates the potential of a field of research that Inquiring from various disciplines about a particular actor, the Jews, recomposes a series of perspectives on the local, the national and the transnational. This paper aims to outline what were the horizons of inquiry and the ways in which these developments have enabled the visibility and local recognition of Jewish studies.

Keywords: Argentina, Jewish Studies, Universities, research.

\section{Presentación}

El reconocimiento de la extensión y complejidad de la inmigración, institucionalización e integración de los judíos a la Argentina hizo de esta experiencia histórica el caso más estudiado dentro del creciente campo de los estudios judíos latinoamericanos. Los primeros trabajos de investigación sistemáticos, que sentaron las bases para los estudios posteriores, tuvieron lugar, fundamentalmente, en agencias y universidades fuera de la Argentina. Si bien el interés de investigadores y centros de investigación extranjeros continuó y aumentó con el tiempo, diversos investigadores e investigadoras afiliados a distintas universidades y agencias de investigación argentinas fueron sentando las bases de una tradición local. Este proceso no solo encontró una dinámica nueva en la última década, sino que además implicó la ampliación del espectro de problemas abordados a partir del diálogo con las agendas académicas locales. De este modo, tras el interés inicial de las primeras investigaciones en temas tales como los procesos de migración e integración, los procesos de institucionalización comunitario y la 
producción literaria ${ }^{1}$, en los últimos años encontramos investigaciones sobre temas tales como la "cuestión judía" en los contextos de violencia política, el lugar de lo "judío" en los procesos de elaboración y transmisión de la memoria, las diversas formas o mecanismos bajo los cuales los judíosinstitucionalizados y no afiliados- participan en la escena política nacional, etcétera. Este desarrollo, que fue de la mano de la ampliación del número de investigadores, del acceso a recursos económicos y materiales para la investigación, de su institucionalización en ámbitos académicos, la elaboración de tesis de posgrado, la participación en congresos de diversas disciplinas y temas, y la publicación de libros y artículos, le granjeó un creciente reconocimiento por parte de investigadores pertenecientes a otras áreas temáticas. De este modo, y como se propone mostrar el presente artículo, los estudios judíos producidos desde Argentina han alcanzado una legitimidad en el campo académico local e internacional como consecuencia de una producción sostenida en el tiempo que evidencia las potencialidades de un campo de investigación que al indagar desde diversas disciplinas sobre un actor en particular, los judíos, recompone una serie de perspectivas sobre lo local, lo nacional y lo transnacional.

Este trabajo se propone reseñar cuáles fueron los horizontes de indagación y los modos en qué estos desarrollos han posiblitado la visibidad y reconocimiento local de los estudios judíos. Algunas preguntas servirán como orientadoras de las reflexiones: ¿Cuáles son las distintas líneas de trabajo e investigación acerca de los judíos que se realizan en el país?; ¿En qué medida esos temas dialogan, se inscriben y/o son subsidiarios de la agenda de debates académica local? y ¿Cuáles han sido las vías de “institucionalización” de los estudios judíos en Argentina? Si bien el trabajo busca presentar un panorma amplio de la obra producida, el volumen de tesis, artículos y libros acumulados en los últimos años y la extensión de esto texto, nos impiden dar cuenta de la totalidad. Tomaremos en consideración, por lo tanto, a aquellos trabajos que consideramos más representativos.

\section{¿Cuáles son las líneas de trabajo e investigación acerca de los judíos que se siguen en nuestro país?}

1El campo de los estudios judíos latinoamericanos es deudor de los estudios y la crítica literaria. De algún modo, la investigación en torno a la producción literaria de autores judíos promovió la construcción del campo. Si bien se trata de una dimensión fundacional y que se intersecta con abordajes desde alternativas disciplinares, el presente trabajo se abocará a la problematización de las perspectivas sociohistóricas y de los estudios culturales dejando para otro momento un reflexión, necesaria, sobre el grado de los estudios literarios en esta materia. 
Las primeras investigaciones que sentaron las bases del estudio sistemático de la presencia judía en Argentina, se ciñeron mayormente a la experiencia de colonización e inmigración judía entre fines del siglo XIX y los albores del siglo XX. Si bien la presencia judía en la región se remonta al período colonial a través de la llegada y asentamiento de grupos de sefaradíes y criptojudíos, la migración que sienta las bases demográficas y da forma a la vida social, cultural y política judía contemporánea se inicia a fines del siglo XIX. Entre los países que recibieron un flujo mayor y más sostenido de migrantes judíos se destaca la Argentina que no solo promovió activamente el arribo de inmigrantes, en especial europeos, desde las últimas décadas del siglo XIX, sino que llegó a tener un agente especialmente dedicado a fomentar la inmigración judía. Pero también sobresale porque, gracias a ese contexto inicialmente favorable, se constituyó en una pieza clave del proyecto de la Jewish Colonization Association, organización filantrópica que organizó y financió el traslado de miles de judíos de Europa oriental a colonias agrícolas que creó y administró sobre todo en este país.

Los tiempos, composición y dimensiones de la migración varían de país en país. Siguiendo lo que ocurrió en los principales países de recepción, encontramos una primera oleada que acaba con el inicio de la Primera Guerra Mundial, formada mayoritariamente por judíos de habla ídish del Imperio Ruso y, en un número menor, por migrantes de habla alemana y húngara de Europa central y sefaradíes de lengua árabe de Medio Oriente y del norte de África. Terminada la Guerra y hasta el ascenso del nazismo en Alemania ingresó una segunda corriente formada esta vez en su mayoría por inmigrantes procedentes de Polonia, y en menor escala de Hungría, Checoslovaquia, Marruecos y Siria. A partir de 1933 se desplegó una tercera corriente conformada por judíos alemanes y de otros países de Europa que se sentían amenazados por el antisemitismo y el nazismo en Europa. La ola de refugiados disparada por la violencia nazi se topó con un creciente clima nacionalista y antisemita en varios países de América Latina que se tradujo en limitaciones legales, abiertas o veladas, para la entrada de judíos. Algunos países, como República Dominicana o Bolivia (Bieber, 1999; Spitzer, 1999; Allen, 2009; Hoffman, 2016), se mantuvieron abiertos al ingreso de refugiados. Esto no significó que no llegaran a Buenos Aires sino que en muchos casos debieron hacerlo de manera ilegal y sorteando numerosos obstáculos.

Esta perspectiva fue abordada, mayormente, por investigadores radicados en Israel y los Estados Unidos de América (Winsberg, 1963; Sofer, 1982; Avni, 1991; Senkman, 1984 y 1991, Levin, 1998; Bar Shalom, 2014). No obstante, algunos trabajos fueron realizados en el país atendiendo algunas 
singularidades. Por ejemplo, la investigación pionera de Boleslao Lewin (1971) que sistematizó información en torno de la llegada de inmigrantes judíos desde el período colonial hasta comienzos del siglo XX. Más cerca en el tiempo se destaca el trabajo de Pablo O`Dwyer (2006) que aborda la historia regional del Alto Valle del Río Negro a través del origen y formación de la Colonia Rusa. Esta investigación reconstruyó los modos de asentamiento de los judíos en un período que se inicia en 1905 y que concluye con el decaimiento de la Colonia hacia fines de los años cincuenta. El trabajo refiere, además, a los aspectos sociales y culturales de los inmigrantes rusos de religión judía llegados a tierras del Estado argentino situadas al Este de lo que se conoce como Colonia General Roca. En una perspectiva similar se inscribe el trabajo de Sebastián Klor (2007) sobre los factores que motivaron el asentamiento de judíos en Córdoba y cuálesd fueron sus rasgos distintivos.

El tópico de la inmigración se complementa con la bibliografìa acerca de los procesos de institucionalización y de integración social, política y cultural de la vida judía en el país. No obstante, una de las características que puede señalarse en relación a la bibliografía sobre los procesos de institucionalización de la vida judía en Argentina en su énfasis con las corrientes sionistas en el interior de las instituciones centrales (Mirelman, 1998; Avni, Op. Cit; Schenkolewski-Kroll, 1996) Sin embargo, esta mirada tendió a estar situada en la dinámica interna de las confrontaciones institucionales antes que el modo en que los judíos interactuaron con otros actores de escala nacional y/o otros colectivos étnico-nacionales.

Dos excepciones han sido los trabajos de Leonardo Senkman (2007) y Raanan Rein (2011). El primero de ellos analiza los modos en que los judíos argentinos construyeron y reconstruyeron sus identidades colectivas a través de una negociación permamente con dimensiones culturales, políticas, religiosas, ya sean de carácter nacional o transnacionales. El segundo aborda una serie de temas tan diversos como la prensa, la política argentina o el fútbol desafiando los sesgos de lo que considera es la perspectiva dominante en el tratamiento de lo judío: el acento en el excepcionalismo, cierto esencialismo en la reproducción de valores culturales, en la pertenencia a una comunidad y en los vínculos siempre favorables de Israel con las comunidades diaspóricas y en la homogeneidad de estas. Asimismo identifica áreas desatendidas, como los estudios de género. 
Retomando estos horizontes, las actuales líneas de investigación tienden a interpelar un núcleo más amplio de perspectivas que permitan comprender los modos en que se desplegó la vida judía en Argentina en relación- a veces armoniosa, otra negociada y en ocasiones conflictiva- a un universo más amplio de problemas: la cuestión de género, los judíos "no afiliados”, la delincuencia, las publicaciones periódicas y las editoriales, la religión, el cine y las memorias de la represión militar, entre otras. (Rein y Brodsky, 2012; Lewis Nowen, 2013)

El tema se complementa con trabajos realizados sobre las particularidades que tuvieron algunos de los grupos migratorios en relación a su lugar de origen. En este sentido, resulta iluminador, por ejemplo, el trabajo de Daniel Bargman (2011) sobre los procesos socioculturales que protagonizaron los inmigrantes judeo-polacos en Argentina, indagando en el modo en que construyeron un perfil identitario como colectivo étnico. Desde una perspectiva similar se encuentra la investigación desarrollada por Susana Brauner (2009) sobre los derroteros y tensiones que suscitó la organización de la vida judía- ya sea institucional, social y religiosa- entre los judíos de origen sirio. Este trabajo, además, se caracterizó por la amplitud de su registro temporal: las fuentes consultadas abarcan la totalidad del siglo XX.

Un tercer eje de investigación lo constituye el relevamiento y análisis de la emergencia y desarrollo de las distintas corrientes políticas judías en el país. Si bien estas estuvieron estrechamente ligadas a los tiempos y dinámica de los centros políticos europeos primero, y norteamericano e israelí después, adquirieron grados y modalidades distintas. Esto se percibe en las distintas variantes del sionismo, el bundismo, el comunismo, e incluso, aunque de un modo menor y temporalmente más acotado, del anarquismo. En los países de la región con mayor presencia judía- como es nuestro caso- los tres primeros movimientos políticos llegaron a desplegar sus propias redes institucionales y educativas, promovieron publicaciones periódicas y la edición de libros y se disputaron el control de las principales instituciones comunitarias y políticas. (Kahan, 2003; Dujovne, 2008) Hacia fines de la década de 1940, y en especial tras la creación del Estado de Israel, el sionismo, en su vertiente progresista, llegó a hegemonizar la vida cultural y política de todas las comunidades judías de la región. (SchenkolewskiKroll, 1996)

Si bien, tal y como sucedió en otras latitudes, la disputa por la lengua nacional judía fue uno de los ejes 
fundamentales de controversia (Krupnik, 2006), el pasaje al castellano como lengua dominante de los judíos latinoamericanos -excepto en Brasil-, fue un elemento distintivo. El progresivo dominio del castellano puso a la Argentina en un lugar central como mediador intelectual entre la producción y orientaciones políticas de los centros y el conjunto de la región. No fue casual, pues, que muchas organizaciones políticas judías internacionales decidieran abrir o afianzar su presencia regional con oficinas y sedes en Buenos Aires hacia la segunda mitad de la década de 1940.

Pero, a su vez, la política judía debe ser contemplada en el marco de la propia historia nacional. Es decir, el contexto del país definió sus posibilidades y límites, y planteó desafíos particulares; también condicionó los modos de interacción entre partidos políticos judíos y los nacionales, a la vez que entre las organizaciones centrales y los poderes públicos. Algunos trabajos comienzan a avanzar sobre la integración y participación de personas de origen judío en la arena política nacional, en tanto individuos y no como representantes o miembros de la comunidad judía. Donde, no obstante, lo judío puede aparecer y tener alguna clase de relevancia en función de la trayectoria personal y el contexto.

En este sentido, resultan iluminadores algunos trabajos realizados en el exterior acerca de los vínculos con el peronismo (Bell, 2002; Rein, 2015), el Partido Comunista (Kerseffeld, 2012) y las izquierdas durante la segunda mitad del siglo XX (Gurwitz, 2016). Estos trabajos ponen en evidencia las ligazones y redes de sociabilidad política entre las organizaciones judías y la arena política nacional. En esta perspectiva se inscribe la investigaciones realizadas por Nerina Visacovsky (2015) e Israel Lotersztain (2014), quienes proponen un acercamiento al universo institucional, educativo e intelectual judeocomunista- una de las vertientes ideológicas y políticas más definidas e importantes de la comunidad judía argentina durante gran parte del siglo veinte. Su trabajo pone el foco en la intersección entre las dimensiones étnicas, idiomáticas, culturales y políticas para reponer las estrategias de reproducción identitaria, las disputas con otros sectores dentro de la comunidad judía, y la posición de este espacio dentro de un marco nacional marcado por la presencia de fuerzas políticas de corte anticomunista y antisemita.

Estas perspectivas resultan reveladoras no solo por lo que puedan decirnos acerca de los vínculos de los judíos con la política nacional sino también por lo que abordan acerca de la propia historia nacional durante el siglo XX. Tanto los trabajos de Bell (2002), Rein (2015) y Visacovsky (2016) nos permiten reconocer, por ejemplo, cómo operaron los discursos nacionalistas de diverso tipo sobre la 
representación de lo judío en el país y, en este sentido, entender cuáles fueron las estrategias que un amplio conjunto de actores desplegó para confrontar, dialogar o servirse de las narrativas nacionales.

El impacto que tuvo la prédica de organizaciones nacionalistas cimentó, a su vez, una amplia bibliografia sobre el antisemitismo en Argentina. Este fenómeno, de algún modo, excede el propio caso nacional: los estudios sobre el desarrollo de la vida judía en América Latina hacen un especial hincapié en el lugar que las narrativas y prácticas del antisemitismo tuvieron en estas sociedades. Si bien algunos de estos trabajos no se inscriben en el campo de los estudios judíos, que el estudio del antisemitismo no es tan ajeno a la experiencia judía en la medida en que tuvo efectos concretos en la identidad y prácticas individuales y colectivas judías.

En este sentido, han resultado centrales los trabajos de Senkman (1989) y Finchelstein (2008) para comprender a través de qué mecanismos y agentes el odio contra los judíos ocupó un lugar preponderante en las agendas programáticas de diversas organizaciones en contextos específicos. En esta línea, Lvovich (2003) hace un aporte significativo a través de un estudio minucioso sobre la recepción del discurso antijudío en Argentina, entre fines del siglo XIX y mediados del siglo XX, atendiendo a cómo la narrativa antisemita tuvo repercusión entre las organizaciones nacionalistas. A través del relevamiento de publicaciones e intervenciones de intelectuales y religiosos (católicos), la investigación visibiliza cómo un discurso sobre el "complot judío mundial" permitió poner bajo sospecha el desarrollo de la vida judía en Argentina.

Sin embargo, uno de los tópicos destacados a través del cual se constituyó el análisis en torno al antisemitismo ha sido la recepción y resignificación del nazismo en estas latitudes. Una amplia bibliografía- más de carácter periodística que académica- asoció a al país con el nazi-fascismo a partir, sobre todo, de considerarlo como tierra receptora de nazis tras la derrota alemana en la Segunda Guerra Mundial. No obstante, diversas investigaciones matizaron el impacto que tuvo esa inmigración aunque señalando las vicisitudes que tuvo, también, la recepción de judíos en América Latina.

Las investigaciones sobre el caso argentino han indagado diversos aspectos: desde cómo se movilizó la comunidad de alemanes (Newton, 1995) hasta las movilizaciones del antifascismo en el país (Bisso, 2005) pasando por las posiciones de la cúpula eclesiástica (Ben Dror, 2003) y el impacto y recepción 
de la experiencia del nazismo en el campo cultural argentina (Klich, 2002.; Sosnowski y Senkman, 2009). En lo que respecta al desarrollo de la vida judía resulta relevante el trabajo de Friedmann (2010) que se centra en la experiencia de Das Andere Deutschland (La Otra Alemania), un grupo de exiliados alemanes antinazis establecidos en Argentina, entre los que se encontraban judíos y que suscitó tensiones en el interior de la comunidad alemana en Argentina por la posición en relación al nazismo. En una perspectiva similar se encuentran un núcleo de trabajos que indagan en las posiciones que asumieron diversos estratos de la dirigencia judía local frente a las denuncias sobre la presencia nazi en el país (Avni, 1995; Rein, 2001, Kahan, 2003)

La cuestión del antisemitismo se complementa con una amplia bibliografia acerca del desarrollo de la vida judía en contextos dictatoriales- particularmente, durante la última dictadura militar ocurrida en el país (1976-1983). Estas investigaciones han analizado, mayormente, el carácter antisemita de estos regímenes (Warszawsky, 1995; Jmelnitzky y Galante, 2002; Finchelstein, 2008), las posiciones que asumieron las dirigencias comunitarias frente a la violación sistemática de los derechos humanos (Klich, 1989; Barromi, 1995 y 1999; Mirelman, 1995; Senkman, 1995; Rosemberg, 2010, Katz; 2011; Schenquer, 2013 y Kahan, 2015) y cómo ésta afectó a una parte de la población judía. (Sznadjer y Roniger, 2004; Herbert, 2007; Rein, 2010)

Como se podrá advertir, el desarrollo que tuvo está temática evidencia, en primer lugar, la centralidad que tuvo la "cuestión judía" en el abordaje de la propia dictadura militar. Pero, en segundo término, nos permite considerar que los debates acerca de cómo operó la dinámica represiva en torno a un amplio espectro de actores identificados - o no tanto- con lo judío otorgaron al caso argentino una dimensión singular en torno a las narrativas que sostuvieron que una porción significativa de la población de origen judío fue víctima del secuestro y la desaparición forzada durante aquellos años.

Ésta bibliografìa consagró, mayormente, una representación estandarizada acerca del período: la dictadura fue antisemita, la dirigencia comunitaria "colaboracionista" y algunos pocos se atrevieron a denunciar lo que aconteció en el país durante la vigencia del terrorismo de Estado. Solo los trabajos más recientes- inscriptos en los debates académicos locales sobre el período dictatorial- pudieron poner en suspenso y revisar algunas de las hipótesis al respecto. (Schenquer, 2013; Kahan, 2015) 
Como en el caso del antisemitismo, una de las perspectivas que dialogó lateralmente con los estudios judíos fue la que se inscribe entre el campo de las relaciones internacionales y los estudios culturales sobre la guerra; con especial énfasis en las posiciones y recepción del conflicto árabe-israelí. En este sentido, merecen destacarse un conjunto de trabajos que han relevado la forma en que el conflicto interpeló a diversos actores en el país. (Klich, 1994) Estos trabajos han podido establecer el modo en que fue recibido y resignificado el conflicto árabe-israelí en Argentina y cómo afectó y se posicionaron diversos agentes de la comunidad judía (Avni, 2000; Senkman, 2000; Rein, 2001)

En este sentido, las investigaciones producidas en el ámbito local han resultado iluminadoras aunque, aún, incipientes. El trabajo pionero de Klich (1994 y 2016) analiza las diversas posiciones en torno a la partición de Palestina (1947) de los partidos políticos mayoritarios en Argentina y recompone las tensiones al interior del cuerpo diplomático en relación a la sanción de Naciones Unidas- una perspectiva que retoman Botta (2011) y Fabani (2016). La pesquisa de Saborido (2009) y Fiszerman (2016) ahondan en las posiciones que tuvieron los partidos políticos tradicionales de izquierda- el Comunista y el Socialista- entre la partición de Palestina y la Guerra de Iom Kipur (1973).

La investigación desarrollada por Méndez (2008) aborda cómo operaron las organizaciones étniconacionales de árabes y judíos sobre las decisiones de la política exterior argentina- perspectiva similar a la que trabajan Setton y Montenegro (2016) en relación a la Federación de Entidades Palestinas. Finalmente, la compilación de Kahan (2016) reúne una serie de artículos que relevan el modo en que un conjunto amplio de actores se posicionó en torno del conflicto árabe-israelí entre 1947 y 2011 muchos de ellos citados en los párrafos anteriores.

Un aspecto que puede destacarse es el poco desarrollo que tuvieron las investigaciones sobre la dinámica de la vida religiosa judía en Argentina. Recién en los últimos años ha comenzado a haber una atención mayor al fenómeno ligado a los procesos de reortodoxización. Esta "laguna" es interesante y comprensible porque evidencia el carácter preponderante que tuvieron las investigaciones sobre los procesos de inmigración y secularización de los judíos. Será recién hacia fines de 1980, cuando se inicia una nueva fase de actividad extendida de algunas corrientes ortodoxas, que la dimensión religiosa comenzó a ser un tópico de investigación. (Fainstein, 2006; Jacobson, 2006; Tank, 2007) Los trabajos de Brauner (2009)- que ya fue citado en este artículo- y de Setton (2010) evidencian un 
desarrollo de esta capítulo de los estudios judíos en la agenda académica local. Este último, particularmente, problematiza las formas de adscripción identitaria que sostienen judíos en proceso de ortodoxización en Buenos Aires poniendo en suspenso algunos sentidos acerca de los procesos de incorporación de jóvenes a movimientos religiosos en un contexto nacional en el que el fenómeno no se ciñe sólo al caso judío.

Finalmente, reconocer un universo de trabajos cuya centralidad es la de recomponer y analizar la dinámica compleja del campo cultural judío- ya sea en el interior de sus marcos institucionales o en diálogo con la escena nacional. En los últimos años, sin embargo, con la ampliación y diversificación del campo de estudios judíos latinoamericanos, la música (Fabro, ...), el teatro (Zayas de Lima, 2001), cine (Falicov, 2011; Tal, 2010), la televisión y la edición han comenzado a recibir una mayor y más regular atención. Esta nueva generación de estudios aborda tanto la representación de lo judío y los judíos en las obras, como el papel de individuos judíos como productores, mediadores y modernizadores culturales.

En este campo se destacan dos investigaciones recientes. El trabajo de Dujovne (2014) toma al libro "judío" como objeto para indagar la formación de la cultura judía argentina, así como el cambiante papel de Buenos Aires en la geografía transnacional de la cultura judía. Se interesa tanto por el mundo de actores que participan en la producción y circulación editorial, y que establecieron y dinamizaron los contactos con los principales centros intelectuales judíos de la Diáspora e Israel, como por los modos en que la palabra impresa funcionó como medio de comunicación transnacional y como ámbito de experimentación y combate político-cultural. A su vez, la compilación de Skura y Glocer (2016) reúne trabajos de los principales especialistas en torno al teatro en idish y la cultura popular judía argentina que, paulatinamente, comienza a ser estudiado de manera sistemática.

Esta ampliación de las perspectivas temáticas que aquí se reseñan están íntimamente ligadas al proceso de institucionalización de los estudios judíos en Argentina. A diferencia de las investigaciones producidas en un contexto de baja densidad institucional, caracterizados por su vinculación con perspectivas de abordaje de lo judío ligadas a centros externos, la ampliación descripta es el resultado de las condiciones materiales y sociales que la habilitan para la producción de una masa crítica de trabajos que permiten construir una agenda de investigación en diálogo on otros centros pero con 
autonomía de estos.. Sobre este punto avanzaremos en los apartados siguientes.

\section{¿En qué medida esos temas dialogan, se inscriben y/o son subsidiarios de la agenda de debates académica local?}

Debido a las características de los estudios judíos en Argentina y sus derroteros de legitimación en el campo académico, gran parte de su producción dialogó con los estudios migratorios. O mejor dicho, fue en el seno de los estudios migratorios que se forjó parte fundacional de la producción acerca de la experiencia judía en el país- como se señala en el primer apartado. Esas pesquisas tenían por objeto, en gran medida, dar cuenta de cómo había sido el proceso de inmigración de los judíos en Argentina y de qué modo se habían organizado y/o integrado a la escena nacional.

Esta perspectiva se complementó con aquellos trabajos dirigidos a indagar en las prácticas y narrativas antisemitas en el país. De algún modo, la investigación en torno a los discursos refractarios de la presencia judía en Argentina permitieron reconocer las estrategias, reacciones e intervenciones en la esfera pública desplegadas por un amplio conjunto de actores con diverso grado de identificación con lo judío.

Sin embargo, como han problematizado Rein y Lesser (2008), los estudios sobre la experiencia judía pueden ser reveladores si se la pone en relación con el estudio de otros colectivos sociales- ya sea étnicos, religiosos, nacionales, etc. El trabajo de Klich (2006) sobre árabes y judíos, por ejemplo, permitió identificar algunas particularidades de la experiencia judía argentina a la vez que reconocer lugares de encuentro, temas de debate y formas afines de percibir las políticas de nacionalización promovidas por el Estado nacional durante gran parte del siglo XX.

En este sentido, la pregunta en torno a los diálogos sostenidos entre los estudios judíos desarrollados en Argentina y otras agendas de grupos académicos locales puede resultar ilustrativa de cómo se vincularon horizontes de trabajo que enriquecieron las perspectivas de investigación. Un estado de la cuestión sobre los estudios judíos en el país debe comprender, además, los modos en que se construyen los problemas de investigación en relación a los ámbitos en los cuales se insertan los investigadores afines a la temática. 
El proceso de constitución de uno de los programas dedicados al estudios de la experiencia judía en Argentina, el Núcleo de Estudios Judíos del Instituto de Desarrollo Económico y Social (NEJ/IDES), que ha podido ir construyendo su legitimidad a la vez que haciendo visible el aporte de sus investigadores al campo académico local. En este sentido, la radicación del NEJ en el IDES fue el resultado del diálogo sostenido con Elizabeth Jelin, por entonces directora del Instituto y responsable del Núcleo de Estudios de Memoria (NEM/IDES)- de este punto nos ocuparemos en el último apartado.

El vínculo entre los estudios judíos y los de memoria abarcó diversas perspectivas. En primer término, la inserción de algunos de los miembros del NEJ- Kahan y Schenquer- en las sesiones de trabajo del NEM en vistas de que sus objetos de estudios estaban interrelacionados: ambos investigaban sobre la experiencia de la vida judía argentina durante los años del régimen dictatorial. En segundo término, los debates y perspectivas se aunaban en una dimensión más conceptual: la cuestión de la memoria judía y la centralidad del Holocausto para abordar la experiencia del terrorismo de Estado formaban parte de una agenda compartida entre investigadores de ambos programas.

Esta pregnancia de los abordajes de memoria en los estudios judíos tuvo, además, un correlato en otras propuestas de investigación. Si en el caso argentino, al menos, los estudios de memoria se ciñeron en su origen- es decir, en el proceso de constitución de legitimidad en el campo de los estudios sociales- al abordaje de los modos en que era recordado el pasado reciente caracterizado por la política criminal del último régimen dictatorial, esta perspectiva se fue ampliando. El modo en que es recordado el pasado contemplaría, también, las experiencias de grupos migratorios, perspectivas de género, el mundo del trabajo. (Jelin, 2017)

En este sentido, resultan ilustrativos los trabajos sobre la colonización judía de la provincia de Entre Ríos y Santa Fe realizados por investigadores consagrados: Patricia Flier (2011), Judith Freidenberg (2013) e Iván Cherjovsky (2016). La primera de ellas analiza la experiencia de la colonización agraria en Colonia Clara retomando las expectativas y demandas de los colonos, sus instituciones sociales, culturales y políticas e indagando en la voz de los colonos asentados en las tierras entrerrianas. Este trabajo reconstruye las tensiones y los enfrentamientos con la empresa colonizadora, el desasosiego de los que fueron vencidos por la naturaleza o por el régimen económico, los alcances y limitaciones de 
los establecimientos escolares y las entidades religiosas para explicar también las razones del abandono de estas colonias. El trabajo de Freidenberg repone, a través de un abordaje etnográfico sobre las memorias del poblamiento judío en una de las colonias de la provincia, la historia acerca de cómo fue ese proceso y en qué medida esa inmigración impactó en la formación de la nacionalidad argentina. Finalmente, el trabajo de Iván Cherjovsky (2016) aborda el proceso de colonización judía en Argentina en Moisesville a la luz de estas perspectivas interpretativas que problematizan cómo es recordado aquel proceso por quienes aún viven en las colonias judías en Santa Fe.

No obstante, no todos los diálogos se orientan hacia los estudios de memoria y el pasado reciente. El trabajo de Damián Settón (2010), por ejemplo, forma parte de un proyecto más amplio destinado a comprender las formas de la religiosidad en Argentina. Allí el trabajo sobre los judíos está en relación con las nuevas formas de adscripción al cristianismo, la visibilización del islam en el país y otras formas de religiosidad popular. Lo mismo podríamos decir del trabajo de Alejandro Dujovne (2014) sobre el libro judío que se inscribe en el creciente campo local y regional de estudios sobre el libro y la edición.

En esta perspectiva, entre las estrategias desarrolladas por el NEJ vale la pena reseñar la experiencia de las Jornadas de Trabajo que sirvieron como ámbitos donde reconocer los abordajes comunes entre investigadores situados en diversas agendas de trabajo. En noviembre de $2010^{2}$, por ejemplo, tuvo lugar la primera de ellas con el objeto de problematizar los modos en que diversos grupos migratorios se posicionan y activan políticamente en contextos nacionales frente a problemáticas vinculadas a sus territorios de origen. Durante el desarrollo de la misma se presentaron trabajos sobre japoneses, coreanos, palestinos, bolivianos, paraguayos y argentinos en los Estados Unidos de América. La conferencia de cierre, dictada por Elizabeth Jelin, puso en consideración un conjunto de cartas de origen familiar, escritas en idish, que describían las percepciones que dos jóvenes vinculados afectivamente tenían sobre la expansión del nazismo en dos orillas distantes: Alemania y Eldorado (Misiones, Argentina) (Jelin, 2009) 
En el año 2013, durante las segundas Jornadas, se abordó la recepción del conflicto árabe-israelí en Argentina $^{3}$. Las sesiones de trabajo indagaron sobre un diverso conjunto de actores a través de un amplio margen temporal: las posiciones de diplomáticos argentinos durante la partición de Palestina (1947) y en parte de los años de la gestión kirchnerista (2003-2011), las posiciones de diversos partidos políticos y agrupaciones de izquierda- el Partido Comunista Argentino, el Partido Socialista, la organización Montoneros, el ICUF- intelectuales y asociaciones religiosas y étnico-nacionalespalestinos, ortodoxos judíos, judíos sirio-libaneses, etc.

Finalmente, las terceras Jornadas se propusieron reunir a investigadores cuyos abordajes hayan indagado el modo en que el Holocausto fue debatido en el espacio público en Argentina ${ }^{4}$. Los trabajos presentados permitieron reconocer la recepción temprana en el país de los debates en torno al exterminio de los judíos europeos y las tensiones posteriores en torno a las formas de recordación y representación de aquella experiencia. La jornada concluyó con una conferencia de George Bensoussan (Memorial de la Shoah, París) acerca de los usos públicos de la memoria del Holocausto.

Estos encuentros constituyeron ámbitos de intercambio que, a su vez, permitieron ampliar las condiciones de reconocimiento inter pares. De modo que el debate alrededor de las comunidades de inmigrantes, el conflicto árabe-israelí y/o el Holocausto evidenció los cruces de perspectivas, preguntas y modos de abordar experiencias que interpelan a un amplio conjunto de actores e investigadores. Los diálogos en torno a temas relevantes, ya sea de los estudios judíos o de los actores que estos estudios pesquisan, fueron solidarios en el reconocimiento de los alcances de los estudios judíos en la agenda académica local.

A su vez, debe reconocerse que el vínculo no es unidireccional ni jerarquico: no solo los estudios judíos se han nutrido del diálogo con otras agendas académicas sino que las investigaciones producidas dentro del campo han permitido revisar algunas hipótesis de aquellas agendas. En este sentido, el trabajo de Kahan (2009) sobre la vigilancia a las instituciones judías de la ciudad de La Plata por parte de la Dirección de Inteligencia de la Policía de la Provincia de Buenbos Aires (DIPBA) puso en discusón la noción de "archivos de la represión" como circunscriptos a los acervos de instituciones de las fuerzas represivas. El trabajo de Malena Chinski (2011) reconoció de qué modo las memorias acerca del

3 http://estudiosjudios.ides.org.ar/files/2012/02/Israel-Palestina.jpg

4 http://estudiosjudios.ides.org.ar/files/2015/11/3\%C2\%AAJornadaNEJ.gif 
Holocausto tuvieron un derrotero temprano en Buenos Aires, a través de una colección de libros en idish, matizando la noción acerca de una memoria que se constituyó en la década del sesenta.

Asimismo, esta legitimidad no se construyó sólo en relación al campo académico local ni, tampoco, sólo entre investigadores. En 2017 tuvo lugar el Simposio sobre Diáspora y Genocidio, co-organizado entre el NEJ y el Center for the Study of Genocide and Human Rights (Rutgers University) que contó con la participación de investigadores y miembros de organizaciones de la sociedad civil dedicadas a la recordación de diversas experiencias de crímenes masivos. ${ }^{5}$ Los diálogos sostenidos durante el encuentro permitieron reconocer las particularidades de los casos abordados- el genocidio armenio, el Holocausto, el genocidio en Guatemala, las dictaduras militares del Cono Sur- así como los abordajes diferenciados- aunque vinculados- entre actores e investigadores.

Esta apertura hacia el campo extra-académico resultó central, incluso, para ampliar los horizontes de indagación del propio campo de los estudios judíos. En este sentido los encuentros sostenidos con escritores- Javier Sinay, Laura Haimovichi, Julián Gorodischer- y filósofos- Darío Sztajnszrajber, Pablo Hupert y Emmanuel Taub-, por ejemplo, permitieron reconocer en otras formas de "abordar" lo

judío algunas dimensiones acerca de cómo contemplar las propias alternativas de la investigación académica: ampliando fuentes, reconociendo nuevas preguntas, interpelando nuevos escenarios, etc.

\section{¿Cuáles fueron las vías de “institucionalización” que atraviesan los estudios judíos en Argentina?}

Si bien la institucionalización de los estudios judíos ha sido diversa, en la mayor parte de los casos se trató inserciones instiucionales individuales. Esto es, investigadores dedicados a temas judíos afiliados a distintos centros y programas académicos. En este caso nos ceñiremos al caso del NEJ-IDES por tratarse de una experiencia colectiva y de trayectoria sostenida. Está claro, sin embargo, que los estudios judíos en Argentina no se inician con el Núcleo de Estudios Judíos.. Hubo experiencias previas- como el Grupo de Investigación sobre el Colectivo Social Judeo-Argentino que fuera dirigido por Javier Pelacoff en el Instituto Gino Germani de la Universidad de Buenos Aires (UBA) y el Proyecto Sambation y su revista de Estudios Judíos Latinoamericana que estuviera coordinada por el Rabino Ariel Korob hasta su temprano fallecimiento. Si bien estas experiencias fueron discontinuadas

5 http://estudiosjudios.ides.org.ar/archivos/821 
es posible encontrar investigadores reconocidos que formaron parte de estos equipos y aún están trabajando estos temas.

A la vez, podemos encontrar investigadores que por fuera del NEJ han abordado o están desarrollando investigaciones promisorias acerca de lo judío en Argentina: Esther Cohen de Chernovadura desde la Universidad Nacional de Tucumán, Susana Brauner desde la Universidad Argentina de la Empresa, Nerina Visacovsky en la Universidad Nacional de San Martín (UNSAM), Germán Friedmann (UBAUNSAM) o los ya citados Susana y Daniel, más Suana Skura (UBA) y Silvia Glocer (UBA-Biblioteca Nacional) o Silvia Hansman (IWO), para dar algunos ejemplos. Sus trabajos han permitido tener un conocimiento más cabal sobre el desarrollo de la vida judía en Argentina- casi todos reseñados en el primer apartado de este trabajo.

En este panorama caracterizado por múltiples abordajes tiene su origen el NEJ-IDES. La experiencia se fraguó de un modo artesanal en sus orígenes: los encuentros en diversas jornadas y congresos locales de, por entonces, becarios y jóvenes investigadores que realizaban sus tesis de posgrado sobre temas y/o actores judíos permitió reconocer una horizonte en común y una vacancia en torno a los espacios de diálogo y formación en estas temáticas. Producto de los cruces sostenidos en estos ámbitos comenzó a construirse una dinámica de encuentro que habilitaría las lecturas compartidas, la discusión de textos de elaboración propia de sus integrantes y la socialización de información respecto de archivos, jornadas específicas, seminarios de posgrado, etc.

Este proceso de institucionalización conjugó una serie de decisiones tomadas a conciencia con el acompañamiento de otros y otras colegas que fueron solidarios del desarrollo del Núcleo de Estudios Judíos. No obstante, la experiencia no podría haberse sostenido por una docena de años si no hubiera habido un contexto que diera la ocasión para mantenerla. En este sentido, cualquier reseña sobre el proceso de institucionalización- y de reconocimiento- de los estudios judíos en Argentina debe reparar en la ampliación del sistema de investigación en ciencia y tecnología que caracterizó al país desde el 2004 hasta el 2015. El acceso a becas del Consejo Nacional de Investigaciones Científicas y Tecnológicas (CONICET) y el financiamiento de diversas universidades nacionales para el desarrollo de programas de investigación individuales y colectivos fueron una condición sine qua non para hacer posible nuestras trayectorias de investigación en ámbitos locales. 
Mientras las primeras reuniones tenían lugar en domicilios particulares, el contacto de algunos miembros del NEJ con Elizabeth Jelin en el IDES habilitó un diálogo para incorporar y promover un Núcleo de Estudios Judíos específicos en el seno de aquella institución. Fue en el 2007 que el NEJ comenzó a trabajar en el IDES y su inscripción en una entidad de carácter privado obedció a dos cuestiones. En primer lugar, fue una decisión consciente la de filiarnos por fuera de las instituciones comunitarias. Si bien allí se encuentran nuestros acervos y actores, el objetivo de construir una legitimidad académica entre pares nos obligó a tomar distancia de las pertenencias a instituciones de la comunidad judía. Nuestro interés, tanto entonces como ahora, radicaba en la consagración de trayectorias académicas que nos permitieran abordar la experiencia judía desde los ámbitos universitarios y de ciencia y tecnología.

Incluso, en momentos álgidos del debate público donde lo judío tuvo centralidad- el conflicto en Medio Oriente, las tensiones entre diversas facciones de la vida política e institucional judía, etc- el NEJ sostuvo una distancia entre los diversos actores y evitamos tomar posiciones públicas- aún cuando nos fueron requeridas. Esta distancia, sin embargo, no nos inhabilitó de participar en diversos encuentros y ámbitos de formación en los que comprendíamos que nuestra intervención correspondía en términos de lo que el sistema universitario y de ciencia y técnica concibe como "extensión" y/o "transferencia de conocimientos producidos".

En segundo lugar, la opción por el IDES respondió a un miedo en el origen- poco sustentado empíricamente con posterioridad- respecto de las tensiones y suspicacias que pudiera generar un programa de estudios judíos en alguna de nuestras universidades públicas en las que cada jalón del conflicto árabe-israelí ponían en el centro del debate la cuestión de Israel, el sionismo y los judíos. Por entonces jóvenes, creíamos que podíamos ser centro de impugnaciones y/o identificaciones con el Estado de Israel o con las posiciones públicas de las instituciones comunitarias. Si bien el ámbito de filiación es el IDES, la mayor parte de los integrantes del NEJ son docentes y/o estudiantes de posgrado en distintas Universidades Nacionales y nuestras perspectivas de trabajo no fueron cuestionadas; en ocasiones, incluso, participamos de debates y jornadas dedicadas, por ejemplo, al conflicto en Medio Oriente. 
Esta estrategia nos permitió, como se desarrolló en los apartados anteriores, compartir agendas de investigación en diálogo con otros equipos de investigación. Esos vínculos, además de acompañar los procesos de formación de los integrantes del NEJ, permitieron reconocer las particularidades de los estudios judíos entre los colegas del IDES y construir horizontes de trabajo compartido con ellos. Así como, por ejemplo, Jelin cerró con una conferencia la primera jornada de trabajo del NEJ, en el 2014 realizamos un diálogo retrospectivo con la antropóloga Rosana Guber- directora del Centro de Antropología Social del IDES, sobre un trabajo que había desarrollado en los comienzos de su carrera de investigación. (1984)

Estos vínculos con otros investigadores constituyeron un puntal del proceso de institucionalización, reconocimiento y legitimación de los estudios judíos desarrollados desde el IDES. Las conferencias, actividades especiales y la recepción de investigadores extranjeros nos permitieron reconocer otros enfoques y ampliar nuestra agenda de investigación a la vez que poner en evidencia los alcances y madurez de las investigaciones que se estaban desarrollando en Argentina. ${ }^{6}$ En este sentido, los diálogos sostenidos con un amplio abanico de colegas fue central en ese proceso de institucionalización pues nos permitió reconocernos en diversos foros y con agendas de investigación que, además de ser locales, están transnacionalizadas.

Este proceso de institucionalización se caracterizó, a su vez, por las propias trayectorias de los integrantes del NEJ. Es decir, la inserción de sus investigadores en programas de investigación de posgrado y el acceso a becas de investigación y perfeccionamiento de diverso tipo- para consulta de archivos, realización de estancias de investigación, participación en Conferencias y Seminarios- que acompañó el desarrollo de tesis e investigaciones. El resultado de estos derroteros ha sido una producción que combinó un alto grado de reflexión conceptual con una fuerte impronta empírica que redundó en un tipo de abordaje que no se ciñó a las historias de las instituciones de la comunidad judía argentina sino que profundizó en un conocimiento más amplio de la experiencia judía en el país. Desde

6 Desde que el NEJ se constituyó en el IDES hemos recibido el acompañamiento de diversos colegas que trabajan desde perspectivas afines: Leonardo Senkman (Universidad Hebrea de Jerusalem), Raanan Rein (Universidad de Tel Aviv), Judit Bokser Liwerant (Universidad Nacional Autónoma de México), Sandra McGee Deutsch (Universidad de Texas-El Paso), Nathaniel Deutsch (Universidad de California-Santa Cruz), Daniela Gleizer (Universidad Nacional Autónoma de México), Saúl Sosnowski (Universidad de Maryland), Jens Anderman), Adam Sacks (Brown University), Ivan Jablonka (Universidad de París XIII), George Bensoussan (Memorial Shoah), Alan Astro (Trinity University), Bogdan Ciurezu (Jewish Community Center of Bucarest), Felicia Waldman (Universidad de Bucarest), Gideon Bohak (Universidad de Tel Aviv) 
perspectivas sociohistóricas, recurriendo a metodologías y conceptualizciones propias de la historia, la sociología, antropología y los estudios culturales, estos trabajos fueron constituyendo un entramado de producciones académicas reconocidas por investigadores ajenos y participantes del propio campo.

\section{Horizontes y desafíos}

Este trabajo se propupo reseñar una de las vías de construcción y legitimación de los estudios judíos en Argentina. Si bien parte de la reseña se concentró en el NEJ/IDES, del que los autores forman parte, el primer apartado pone en evidencia que la cosagración de un campo dedicado al estudio de la experiencia judía en Argentina se caracterizó por la ampliación de las perspectivas y problemas para su abordaje. La incorporación de nuevas temáticas, metodologías y acervos en torno de lo "judío" en Argentina fue producto, a su vez, de una serie de condiciones que viabilizaron los procesos de legitimación e institucionalización. A saber: contar con recursos económicos para el acompañamiento de las trayectorias personales y grupales; la inscripción de los investigadores en la formación de posgrado en agencias universitarias y de ciencia y tecnología; la apertura al diálogo con otros equipos de investigación que en el intercambio han enriquecido nuestra agenda- y viceversa-; la construicción y sostenimiento de una serie de vínculos académicos transnacionales que han acompañado este derrotero.

Sin embargo, y aunque podamos afirmar que los estudios judíos existen en Argentina- es decir, que hay una masa crítica de investigadores e investigadoras dedicadas a pesquisar la experiencia judía que son reconocidas entre sus pares- aún hay una serie de desafíos que debemos contemplar. Por ejermplo, la ampliación y profundización de algunas perspectivas temáticas. Resultan aún marginales o de escaso desarrollo las investigaciones sobre la cuestión de género (Cohen, de Chernovagura, 2016), la vinculación entre los judíos y la escena política nacional, las relaciones con el delito, la experiencia judía en provincias y ciudades donde hubo y hay una migración importante pero que han sido poco o nada estudiadas; solo por enumerar algunas. En este sentido, y como pone en evidencia el trabajo, la riqueza de los estudios judíos en nuestros contextos de producción debe atender a la ampliación de perspectivas; y una profundización del diálogo y los intercambios con otros actores del campo académico. 
No obstante, los estudios judíos en Argentina no se han consagrado solo atendiendo a la escena académica local. Debemos seguir atentos los debates transnacionales que dinamizan el propio campo a la vez que ampliar las redes de circulación y socialización entre investigadores. En este sentido, sería esperable desarrollar la promoción de los estudios judíos a escala regional acompañando a aquellos colegas que insertos en diversas agencias de investigación en Latinoamerica no cuenten con los recursos, el reconocimiento institucional y/o el diálogo asiduo con otros equipos de investigación que habiliten la ampliación temática y de perspectivas.

Este horizonte deseable aparece, sin embargo, problemático. $\mathrm{Si}$, como se mencionó anteriormemte, los estudios judíos precisan de un sistema que acompañe la investigación en el campo de la historia, las ciencias sociales y los estudios culturales, el panorama argentino avisora un futuro complejo.

\section{Bibliografía}

Avni, H. (1983), Argentina y la Historia de la inmigración judía (1810-1950), Buenos Aires, Universidad Hebrea de Jerusalem.

Avni, H. (1995), "Jewish Leadership in times of crisis: Argentina during the Eichmann Affair (19601962),” in P. Medding (ed.), Values, Interests and Identity, Oxford.

Avni, H. (2000), "The Impact of the Six-Day War on a Zionist Community: The Case of Argentina," en Lederhendler, Edit (ed.), The Six-Day War and World Jewry, University Press of Maryland..

Bar Shalom, T. (2014), La desconocida colonización urbana de la JCA en Argentina, 1900-1930., Jerusalem: Zur-On.

Bargman, D. (2011), "Judíos oriundos de Polonia en Argentina: construcciones identitarias y asociacionismo étnico hasta la segunda posguerra” en Kahan, et al, Marginados y consagrados. Nuevos Estudios sobre la vida judía en Argentina., Buenos Aires, Lumiere. 
Bell, L. (2002), The Jews and Perón: Communal Politics and National Identity in Peronist Argentina,1946-1955, PhD Dissertation, Doctor of Philosophy in the Department of History of The Ohio State University.

Gurwitz, B. (2016), Argentine Jews in the Age of Revolt. Between the New World and the Third World, London, Brill.

Kersffeld, D. (2012), Rusos y rojos. Judios comunistas en tiempos de la Comintern, Buenos Aires, Capital Intelectual.

Rein, R. (2015), Los muchachos peronistas judios. Los argentinos judíos y el apoyo al justicialismo, Buenos Aires, Sudamericana.

Visacovsky, N. (2015), Argentinos, judios y camaradas tras la utopía socialista, Buenos Aires: Biblos.

Ben Dror, G. (2003), Católicos, nazis y judíos. La Iglesia Argentina en los tiempos del Tercer Reich, , Buenos Aires, Lumiere.

Bieber, L. (1999), “La Sociedad de Protección a los inmigrantes israelitas: su aporte a la integración de judíos en Bolivia, 1939-1945," Latin American Research Review, Vol. 34, № 2, University of New Mexico.

Bisso, A. (2005), Acción Argentina. Un antifascismo nacional en tiempos de guerra mundial., Buenos Aires, Prometeo.

Brauner, S. (2009).Ortodoxia religiosa y pragmatismo político. Los judíos de origen sirio. Buenos Aires: Lumiere.

Brodsky, A. (2012), "Electing 'Miss Sefaradí,' and 'Queen Esther': Sephardim, Zionism, and Ethnic and National Identities in Argentina, 1933-1971," en Raanan Rein and Adriana Brodsky (eds), The New Jewish Argentina: Facets of Jewish Experiences in the Southern Cone, Leiden: Brill.

Cohen de Chernovagura, E. (2016), Eshet jail. Un contrapunto entre dos mujeres judias., Tucumán, Universidad Nacional de Tucumán.

Cherjovsky, I. (2016), Recuerdos de Moises Ville., Buenos Aires, Teseo.

Dujovne, A. (2008), "Cartografía de las publicaciones periódicas judías de izquierda en Argentina, 1900-1953”, in Revista del Museo de Antropología, Universidad Nacional de Córdoba.

Dujovne, A. (2014), Una historia del libro judío. La cultura judía argentina a través de sus editores, libreros, traductores, imprentas y bibliotecas, Buenos Aires, Siglo XXI. 
Fabani, O. (2016), Política exterior argentina frente al conflicto árabe israelí: ajustes y continuidades entre los dos primeros gobiernos del Frente para la Victoria (2003-2011)” en Kahan, E. (comp.) (2016), Israel-Palestina, una pasión argentina. Estudios sobre la recepción del conflicto árabe-israelí en Argentina, Buenos Aires, Prometeo.

Fainstein, D. (2006), "Secularización, profecía, y liberación: La desprivatización de la religión en el pensamiento judío contemporáneo," Doctoral dissertation in Political Sciences, Universidad Nacional Autónoma de México.

Falicov, T. (2011), "Burman's ode to El Once neighborhood: The lost embrace." en Baron, Lawrence, The Modern Jewish Experience in World Cinema. Brandeis University Press, Massachusetts.

Finchelstein, F. (2008), La Argentina fascista. Los orígenes ideológicos de la dictadura, Buenos Aires, Sudamericana.

Finchelstein, F. (2008), La Argentina fascista. Los orígenes ideológicos de la dictadura., Buenos Aires, Sudamericana.

Fiszerman, E. (2016), "Entre Moscú y Europa: Israel como caso crítico de la vía socialista en Argentina" en Kahan, E. (comp.) (2016), Israel-Palestina, una pasión argentina. Estudios sobre la recepción del conflicto árabe-israelí en Argentina, Buenos Aires, Prometeo.

Flier, P. (2011), “Historia y memoria de la colonización judía agraria en Argentina, 1892-1950”, PhD Thesis, Universidad Nacional de La Plata.

Freidenberg, J (2013), La invención del gaucho judío. Villa Clara y la construcción de la identidad en Argentina, Buenos Aires: Prometeo.

Friedmann, G. (2010), Alemanes antinazis en la Argentina, Buenos Aires, Siglo XXI.

Guber, R (1984), "La construcción de la identidad étnica. Integración y diferenciación en los inmigrantes judíos ashkenazim en la Argentina", en Antropología Argentina 1984, Buenos Aires, Editorial Belgrano.

Herbert, L. (2007), "The History of Argentine Jewish Youth under the 1976-1983 Dictatorship as SeenThrough Testimonial Literature," Senior Honors Thesis, Ohio State University.

Hoffman, A. (2016), Panic Emigration: Jewish Agricultural Settlements in Bolivia and the Dominican Republic, 1935-1960, M.A. dissertation in Latin America Studies, UCLA, 2016. 
Jacobson, S. (2006). "Modernity, conservative religious movements, and the female subject: Newly ultraorthodox Sephardi women in Buenos Aires.” American Anthropologist 108(2): 336-346.

Jelin, E. (2009), "Rosas transplantadas y el mito de Eldorado. Travesías en el tiempo, el espacio, en la imagen y en silecio.", Revista del Museo de Antropología, $\mathrm{N}^{\circ}$ 1, Vol 2, Universidad Nacional de Córdoba.

Jelin, E. (2017), “La conformación de un campo de investigación. Estudios de memoria y género en las ciencias sociales latinoamericanas" en Jelin, E., La lucha por el pasado. Cómo construimos la memoria social., Buenos Aires, Siglo XXI.

Kahan, E. (2003), "La construcción de la identidad judía en la nacionalidad argentina. El vocero del sionismo socialista, Nueva Sión, en tiempos del affaire Eichman (1960-1962)", tesina de licenciatura en Historia, Universidad Nacional de La Plata.

Kahan, E. (2009), Unos pocos peligros sensatos. La Dirección de Inteligencia de la Policía de la Provincia de Buenos Aires frente a las instituciones judías de la ciudad de La Plata, La Plata, Editorial de la Universidad Nacional de La Plata.

Kahan, E. (2015), Recuerdos que mienten un poco. Vida y memoria de la experiencia judía durante la última dictadura militar, Buenos Aires, Prometeo.

Kahan, E. (comp.) (2016), Israel-Palestina, una pasión argentina. Estudios sobre la recepción del conflicto árabe-israelí en Argentina, Buenos Aires, Prometeo.

Katz, P. (2011), “A New 'Normal': Political Complicity, Exclusionary Violence and the Delegation of Argentine Jewish Associations during the Argentine Dirty War," The International Journal of Transitional Justice, № 5, Oxford University Press.

Klich, I. (1989), "Política comunitaria durante las Juntas Militares: la DAIA durante el Proceso de Reorganización Militar”, in Senkman, L., (comp.), El antisemitismo en Argentina, Buenos Aires, Centro Editor de América Latina.

Klich, I. (1994), "Peronistas y Radicales ante las aspiraciones sionistas en Palestina," Desarrollo Económico 133, pp. 75-94.

Klich, I. (comp.) (2002), Sobre nazis y nazismo en la cultura argentina, Maryland, Hyspamerica.

Klich, I. (comp.) (2006), Árabes y judíos en América Latina. Historia, representaciones y desafíos., Buenos Aires, Siglo XXI. 
Klor, S. (2007), "Ser judío / sionista / argentino: la experiencia histórica y socioeconómica de los inmigrantes judíos en Córdoba 1901-1950”, en Revista de la Junta Provincial de Córdoba, segunda época, $N^{\circ} 24,2007$, Córdoba,

Krupnik, A. (2006), “¿Qué les pasa con el idish a estos idishes que escuchan a los Beatles y hablan de revolución?, en AAVV, Buenos Aires idish, Gobierno de la ciudad de Buenos Aires.

Lesser, J. and Rein, R. (2008), "New approachers to ethnicity and Diaspora in Twentieth-Century Latin America" in Lesser, J. and Rein, R. (eds.), Rethinking Jewish-Latin Americans, University of New Mexico Press.

Levin, Y. (1998), De la crisis al crecimiento: El episodio de la colonización judía en la Argentina, fundada por la Jewish Colonization Association - JCA, 1896-1914, Tel Aviv: PhD. dissertation (en Hebreo), Tel Aviv University.

Lewin, B. (1971), Cómo fue la inmigración judía a la Argentina, Buenos Aires: Plus Ultra.

Lewis Nowen, M. (2013), Oy, My Buenos Aires. Jewish immigrants and the creation of Argentine national identity, Albuquerque: University of New Mexico Press.

Lotersztain, I. (2014), "La historia de un fracaso: La religión judeo-comunista en tiempos de la URSS", tesis de Doctorado en Ciencias Socialess, Universidad Nacional de General Sarmiento.

Lvovich, D. (2003), Nacionalismo y antisemitismo en la Argentina, Buenos Aires, Vergara.

Méndez, Norberto, "El rol de las colectividades árabe/islámica y judía de la Argentina respecto del conflicto en Medio oriente (1947-2007)", Tesis de Doctorado en Relaciones Internacionales, Universidad Nacional de La Plata, 2008.

Milgram, A. (Ed.) (2003), Entre la aceptación y el rechazo. América Latina y los refugiados judios del nazismo, Yad Vashem, Israel.

Mirelman, V. (1995), "Las organizaciones internacionales judías ante la represión y el antisemitismo en Argentina," en Senkman, L. and Sznadjer, M., El legado del autoritarismo. Derechos humanos y antisemitismo en la Argentina contemporánea, Buenos Aires, Nuevo Hacer.

Montenegro, S. y Setton, D. (2016), “Trayectorias militantes: formación del ideario de la Federación de Entidades Argentino-Palstinas”, en Kahan, E. (comp.) (2016), Israel-Palestina, una pasión argentina. Estudios sobre la recepción del conflicto árabe-israelí en Argentina, Buenos Aires, Prometeo.

Newton, R. (1995), El cuarto lado del triángulo. La "amenza nazi" en Argentina (1931-1947), Buenos Aires, Sudamericana.

Cuadernos Judaicos ISSN: 0718-8749 
O`Dwyer, P. (2006), Tierra prometida. La colonización judía en el Alto Valle de Río Negro., Editorial de la Universidad Nacional del Comahue.

Rein, R. (2001), Argentina, Israel y los judíos. Encuentros y desencuentros, mitos y realidades, Buenos Aires, Lumiere.

Rein, R. (2010), Argentine Jews or Jewish Argentines? Essays on Ethnicity, Identity, and Diaspora, Boston: Brill, 2010. (En español: Rein, R. (2011), Judios-argentinos o argentinos-judíos. Identidad, etnicidad y diáspora, Buenos Aires: Lumiere)

Rosemberg, D. (2010), Marshall Meyer. El rabino que le vio la cara al diablo., Buenos Aires, Capital Intelectual.

Saborido, M. (2009), "Un viraje inducido: el Partido Comunista de la Argentina y el conflicto de Medio Oriente," Doctoral dissertation, Universidad Complutense de Madrid.

Schenkolewski-Kroll, S. (1996), The Zionist Movement and the Zionist Parties in Argentina, 19351948, The Magnes Press, The Hebrew University, Jerusalem. (en Hebreo: 1948-1935, בארגנטינה (והמפלגות הציוניות התנועה הציונית

Schenquer, L. (2013), “Actitudes sociales en dictadura. Estudios sobre las dirigencias de DAIA y de las instituciones religiosas liberales durante el último régimen militar (1976-1983)," Doctoral dissertation in Social Sciences, Universidad de Buenos Aires.

Senkman, L (1995), "Israel y el rescate de las víctimas de la represión," in Senkman, L. and Sznadjer, M., El legado del autoritarismo. Derechos humanos y antisemitismo en la Argentina contemporánea, Buenos Aires, Nuevo Hacer.

Senkman, L. (1991), Argentina, la Segunda Guerra Mundial y los refugiados indeseables, 1933-1945, Buenos Aires: Grupo Editor Latinoamericano.

Senkman, L. (2000), "Repercussions of the Six-Day War in the Leftist Jewish Argentine Camp: The Rise of Fraie Schtime, 1967-1969," en Lederhendler, Eli (comp.) The Six-Day War and World Jewry, University Press of Maryland.

Senkman, L. (2007), "Ser judío en Argentina: las transformaciones de la identidad nacional”, en Mendes-Flohr, Paul, Assis, Yom Tov and Senkman, Leonardo (Eds), Identidades judías, modernidad y globalización, Lilmod, Buenos Aires. 
Senkman, L. (comp.) (1989), El antisemitismo en la Argentina, Buenos Aires, Centro Editor de América Latina.

Senkman, L. y Sosnowski, S. (2009), Fascismo y Nazismo en las letras argentinas, , Buenos Aires, Lumiere.

Setton, D. (2010). "Judíos ortodoxos y judíos no afiliados en procesos de interacción. El caso de Jabad Lubavitch de Argentina”, Doctoral dissertation in Social Sciences, Universidad de Buenos Aires.

Sinay, J. (2013), Los crímenes de Moises Ville, Buenos Aires, Tusquets.

Skura, Susana and Glocer, Silvia (comps.) (2016), Teatro ídish argentino (1930-1950). Editorial de la Facultad de Filosofía y Letras, Universidad de Buenos Aires.

Sofer, E. (1982). From Pale to Pampa: A social history of the Jews of Buenos Aires, Holmes and Meier, Nueva York

Spitzer, L. (1999), Hotel Bolivia. The Culture of Memory in a Refuge from Nazism, Hill y Wang, New York.

Sznadjer, M. and Roniger, L. (2004), "De Argentina a Israel: escape y exilio," in Yankelevich, P. (comp.), Represión y destierro. Itinerarios del exilio argentino, La Plata, Al Margen.

Tal, T. (2010), “Terror, etnicidad y la imagen del judío en el cine argentino contemporáneo" en Nuevos mundos, Mundos nuevos.

Tank, S. (2007), Juifs d'élection: se convertir au judaisme. Paris, CNRS Editions.

Warszawsky, P. (1995), "Régimen militar, iglesia católica y comunidad judía en la República Argentina," en Senkman, L. and Sznadjer, M. (comps.), El legado del autoritarismo. Derechos humanos y antisemitismo en la Argentina contemporánea., Buenos Aires, Nuevo Hacer.

Wells, A. (2009), Tropical Zion: General Trujillo, FDR, and the Jews of Sosua. Durham, NC: Duke University Press.

Winsberg, M. (1963), Colonia Barón de Hirsch: A Jewish Agricultural colony in Argentina., University of Florida.

Zayas de Lima, P. (2001), Cultura judía. Teatro nacional, Buenos Aires, Editorial Nueva Generación. 